\section{Asynchrony Between Fact and Dogma}

\section{To the Editor:}

Subirà et $\mathrm{al}^{1}$ recently provided an excellent review in this Journal of synchrony problems during mechanical ventilation. One statement in that paper caught my attention: "When the entire period of mechanical ventilation is taken into account, asynchronies are slightly more frequent in pressure support ventilation (PSV) than in volume control continuous mandatory ventilation (VCCMV)." 2 As an author and educator, I can well imagine that statement being repeated in other papers and in textbooks, becoming dogma in the classroom and ultimately carried out as practice (or at least confusion) at the bedside. My intention in this letter is not to criticize the authors on a very well-written paper but rather to examine this one particular statement and, hopefully, prevent misinterpretation by readers unfamiliar with the literature.

On the face of it, the statement should raise suspicion simply because PSV should result in better synchrony than volume control continuous mandatory ventilation. This is because PSV is classified as PC-CSV (pressure control continuous spontaneous ventilation) with set-point targeting, ${ }^{3}$ whereas VC-CMV is classified as volume control continuous mandatory ventilation, also with set-point targeting (as opposed to dual targeting, which provides better synchrony ${ }^{4}$ ). The distinction in classification highlights the fact that PSV delivers only spontaneous breaths for which the patient retains substantial control over timing due to the nature of spontaneous breaths (ie, inspiration is patient triggered and patient cycled $\left.^{3}\right)$. We expect that synchrony problems due to a mismatch of neural and ventilator inspiratory times, therefore, would be less prevalent than for a mode that delivers only mandatory breaths: Inspiration for mandatory breaths is machine triggered and/or machine cycled ${ }^{3}$ according to arbitrary operator-set values, independent of the patient's neural timing.

The study referenced by Blanch et $\mathrm{al}^{2}$ to support the statement quoted above indeed says "We . . . found that (asynchrony index) and (ineffective inspiratory efforts during expiration) were slightly more frequent in PSV compared to [volume control ventilation] or [pressure control ventilation] and this is in contrast with other short-term studies where PSV achieved better results com- pared to [volume control ventilation]." However, they clarified by saying that "Since we studied the entire period of [mechanical ventilation] and the same patient could have been ventilated using different modes, it is difficult to establish conclusions on which mode performed better...".2 More to the point, they speculated that "It may have been that rise time, termination criteria, and pressure support level were set more frequently inappropriately in PSV than in settings used during [volume control ventilation] or PSV."2 Although they "found a higher rate of double-triggering in PSV than in [volume control ventilation] or [pressure control ventilation]," they explained that "In our study, generation of double-triggering could be attributed to the inappropriate setting of cycling-off criteria in PSV."2 One could argue that synchrony problems with PSV are valid data to report if for no other reason than they may indicate a lack of attention to optimum settings. But, that could be said of any mode, and it obscures the larger picture.

The rational selection of the best mode of ventilation for a particular patient at a particular point in time 5 involves 3 steps: (1) identifying the most important of the 3 goals of mechanical ventilation, that is, safety, comfort, or liberation; (2) determining the mode that is both available and has the most appropriate technical design capabilities to serve the goal; and (3) once selected, adjusting the settings of the mode to serve as many of the goals as possible, for example, safe gas exchange with the fewest clusters $^{6}$ of ineffective inspiratory efforts during weaning. With this added perspective, emphasizing the synchrony problems with PSV without adequate context could obscure the fact that the mode has a fundamental design capability (all spontaneous breaths) that better serves the goal of comfort (synchrony) than modes composed of all mandatory breaths, such as VC-CMV and PC-CMV (pressure control continuous mandatory ventilation). And this understanding helps one to appreciate other modes with the same capability and that have other desirable capabilities, such as neurally adjusted ventilatory assist ${ }^{7}$ and proportional assist ventilation. ${ }^{8}$

Time to nip this dogma in the bud.

\section{Robert L Chatburn MHHS RRT} RRT-NPS FAARC

Respiratory Therapy Department Cleveland Clinic Cleveland, Ohio
Mr Chatburn discloses relationships with IngMar Medical and DeVilbiss/Drive Medical.

DOI: $10.4187 /$ respcare.06291

\section{REFERENCES}

1. Subirà $C$, de Haro $C$, Magrans R, Fernández R, Blanch L. Minimizing Asynchronies in Mechanical Ventilation: Current and Future Trends. Respir Care 2018;63(4): 464-478.

2. Blanch L, Villagra A, Sales B, Montanya J, Lucangelo U, Lujan M, et al. Asynchronies during mechanical ventilation are associated with mortality. Intensive Care Med 2015; 41(4):633-641.

3. Chatburn RL, El-Khatib M, Mireles-Cabodevila E. A taxonomy for mechanical ventilation: 10 fundamental maxims. Respir Care 2014;59(11):1747-1763.

4. Volsko TA, Hoffman J, Conger A, Chatburn RL. The effect of targeting scheme on tidal volume delivery during volume control mechanical ventilation. Respir Care 2012;57(8): 1297-1304.

5. Mireles-Cabodevila E, Hatipoğlu U, Chatburn RL. A rational framework for selecting modes of ventilation. Respir Care 2013; 58(2):348-366.

6. Vaporidi K, Babalis D, Chytas A, Lilitsis E, Kondili E, Amargianitakis V, et al. Clusters of ineffective efforts during mechanical ventilation: impact on outcome. Intensive Care Med 2017;43(2):184-191.

7. Di Mussi R, Spadaro S, Mirabella L, Volta CA, Serio G, Staffieri F, et al. Impact of prolonged assisted ventilation on diaphragmatic efficiency: NAVA versus PSV. Crit Care 2016;20(1):1.

8. Bosma KJ, Read BA, Bahrgard Nikoo MJ, Jones PM, Priestap FA, Lewis JF. A Pilot Randomized Trial Comparing Weaning From Mechanical Ventilation on Pressure Support Versus Proportional Assist Ventilation. Crit Care Med 2016;44(6):10981108 .

\section{Asynchrony Between Fact and Dogma-Response}

\section{To the Editor:}

We thank Mr Chatburn for his positive comments on our review. ${ }^{1}$ Chatburn highlights our previous finding 2,3 that asynchronies, in particular, ineffective efforts during expiration, were slightly more frequent in pressure support ventilation (PSV) compared with volume control continuous mandatory ventilation throughout mechanical ventilation. Chatburn rightly points out that, in theory, PSV should result in better synchrony than volume control continu- 
ous mandatory ventilation because PSV delivers only spontaneous breaths, so patients should retain substantial control of the breath. We fully agree with Chatburn's 3 recommendations for selecting the best mode and for adjusting settings to patients' needs. Recently, Tobin ${ }^{4}$ pointed out that "in critical care practice, no area demands greater understanding of physiological principles than ventilator management," and this is particularly true for PSV.

The apparent simplicity of PSV makes it an attractive mode. It is often the mode of choice when the patient's level of consciousness improves and starts to trigger the ventilator. ${ }^{5}$ In this period, it is crucial to ensure optimal trigger sensitivity, appropriate post-trigger inflation (paying special attention to pressure rise time and the duration of the patient's inspiratory effort), and cycling (ie, the transition from inspiration to expiration). ${ }^{4,6,7}$ If the switch over from inspiration to expiration is not in phase with the patient's neural expiration, then expiratory muscles can be activated while the ventilator is still inflating the lungs. Moreover, over-assistance during PSV is common and often results in hyperinflation, which can cause respiratory muscular dysfunction or even atrophy, which favors the occurrence of ineffective efforts during expiration, which causes difficulties during sleep and weaning, and results in a prolonging of mechanical ventilation. ${ }^{4,6,7}$ Importantly, clusters of ineffective efforts during expiration can increase intensive care and hospital mortality. ${ }^{8}$

PSV is not a simple mode; as with any other mode, it requires continuous bedside adjustments to ensure that underrecognized forms of patient-ventilator asynchrony do not go undetected and inadequately treated. All patients on mechanical ventilation are susceptible to asynchronies, in all modes, from intubation to extubation. ${ }^{2}$ The effects of poor patient-ventilator interaction on the outcome could be significant ${ }^{9}$ and warrant urgent investigations.

Carles Subirà MD

Intensive Care Unit

Fundació Althaia

Universitat Internacional de Catalunya Manresa, Spain

\section{Candelaria de Haro MD} Critical Care Center

Parc Taulí Hospital Universitari

Institut d'Investigació i Innovació Parc Taulí (I3PT)

Universitat Autònoma de Barcelona Sabadell, Spain

Rudys Magrans PhD

Institut d'Investigació i Innovació Parc Taulí (I3PT)

Sabadell, Spain

Centro de Investigación Biomédica en

Red en Enfermedades Respiratorias Instituto de Salud Carlos III Madrid, Spain

Rafael Fernández MD PhD Intensive Care Unit

Fundació Althaia

Universitat Internacional de Catalunya

Manresa, Spain

Centro de Investigación Biomédica en

Red en Enfermedades Respiratorias Instituto de Salud Carlos III

Madrid, Spain

Lluis Blanch MD PhD

Critical Care Center

Parc Taulí Hospital Universitari

Institut d'Investigació i Innovació Parc

Taulí (I3PT)

Universitat Autònoma de Barcelona Sabadell, Spain
Centro de Investigación Biomédica en

Red en Enfermedades Respiratorias Instituto de Salud Carlos III

Madrid, Spain

DOI: $10.4187 /$ respcare. 06330

\section{REFERENCES}

1. Subirà $\mathrm{C}$, de Haro $\mathrm{C}$, Magrans $\mathrm{R}$, Fernández $\mathrm{R}$, Blanch L. Minimizing asynchronies in mechanical ventilation: current and future trends. Respir Care 2018;63(4):464-478.

2. Blanch L, Villagra A, Sales B, Montanya J, Lucangelo U, Luján M, et al. Asynchronies during mechanical ventilation are associated with mortality. Intensive Care Med 2015;41(4): 633-641.

3. Blanch L, Sales B, Montanya J, Lucangelo U, Garcia-Esquirol O, Villagra A, et al. Validation of the Better Care ${ }^{\circledR}$ system to detect ineffective efforts during expiration in mechanically ventilated patients: a pilot study. Intensive Care Med 2012;38(5):772-780.

4. Tobin MJ. Physiologic Basis of Mechanical Ventilation. Ann Am Thorac Soc 2018; 15(suppl 1):S49-S52.

5. Esteban A, Ferguson ND, Meade MO, Frutos-Vivar F, Apezteguia C, Brochard L, et al; VENTILA Group. Evolution of mechanical ventilation in response to clinical research. Am J Respir Crit Care Med 2008; 177(2):170-177.

6. Brochard L. Pressure-support ventilation: still a simple mode? Intensive Care Med 1996;22(11):1137-1138.

7. Brochard L, Telias I. Bedside Detection of Overassistance During Pressure Support Ventilation. Crit Care Med 2018;46(3):488-490.

8. Vaporidi K, Babalis D, Chytas A, Lilitsis E, Kondili E, Amargianitakis V, et al. Clusters of ineffective efforts during mechanical ventilation: impact on outcome. Intensive Care Med 2017;43(2):184-191.

9. Rué M, Andrinopoulou ER, Alvares D, Armero C, Forte A, Blanch L. Bayesian joint modeling of bivariate longitudinal and competing risks data: An application to study patient-ventilator asynchronies in critical care patients. Biom J 2017;59(6):1184-1203. 